Florida International University FIU Digital Commons

$7-3-2013$

\title{
Genetic Structure of the Florida Key Tree Cactus, Pilosocereus robinii, using Restriction Site associated DNA (RAD) markers
}

Tonya D. Fotinos

tonya.fotinos@gmail.com

DOI: $10.25148 /$ etd.FI13080703

Follow this and additional works at: https:// digitalcommons.fiu.edu/etd

Part of the Genomics Commons, Plant Breeding and Genetics Commons, and the Population Biology Commons

\section{Recommended Citation}

Fotinos, Tonya D., "Genetic Structure of the Florida Key Tree Cactus, Pilosocereus robinii, using Restriction Site associated DNA (RAD) markers" (2013). FIU Electronic Theses and Dissertations. 914.

https://digitalcommons.fiu.edu/etd/914 


\section{FLORIDA INTERNATIONAL UNIVERSITY}

Miami, Florida

GENETIC STRUCTURE OF THE FLORIDA KEY TREE CACTUS, Pilosocereus robinii, USING RESTRICTION SITE ASSOCIATED DNA (RAD) MARKERS

A thesis submitted in partial fulfillment of the

requirements for the degree of

MASTER OF SCIENCE

in

BIOLOGY

By

Tonya Dee René Simons Fotinos 
To: Dean Kenneth G. Furton

College of Arts and Sciences

This thesis, written by Tonya Dee René Simons Fotinos, and entitled Genetic Structure of the Florida Key Tree Cactus, Pilosocereus robinii, using Restriction Site associated DNA (RAD) markers, having been approved in respect to style and intellectual content, is referred to you for judgment.

We have read this thesis and recommend that it be approved.

M. Patrick Griffith

Joyce Maschinski

Eric von Wettberg, Major Professor

Date of Defense: July 3, 2013

The thesis of Tonya Dee René Simons Fotinos is approved.

$\begin{array}{r}\text { Dean Kenneth G. Furton } \\ \text { College of Arts and Sciences } \\ \hline \begin{array}{r}\text { Dean Lakshmi N. Reddi } \\ \text { University Graduate School }\end{array}\end{array}$

Florida International University, 2013 


\section{DEDICATION}

To my husband Tim who has journeyed with me through the fun, crazy world of biology and plants for thirteen years. 


\section{ACKNOWLEDGMENTS}

I would first like to thank the members of my committee: Dr. M. Patrick Griffith for his guidance in all things Cactaceae, Dr. Jennifer Richards for her advice and support and Dr. Joyce Maschinski for her critical reviews, encouragement and advice. I owe a debt of gratitude to my major professor Dr. Eric von Wettberg for his always timely direction, encouragement and poignant mentorship. I am grateful for his patience and genetic insight to push me towards this emerging technology for this endangered cactus and to broaden my academic knowledge.

I owe gratitude to the MBRS-RISE program at FIU for supporting me in my graduate studies (NIH/NIGMS R25 GM61347). Also, a thank you to the Florida Native Plant Society, who awarded me a research grant to assist with the processing of the Pilosocereus samples. This research was conducted under a grant from the Florida Department of Agriculture and Consumer Services Conservation program awarded to Drs. Eric von Wettberg and Joyce Maschinski.

Thanks to Ericka Witcher for her assistance with acquiring ample non-endangered cacti material to work with, witty mental and toddler distraction. Thanks to Dr. Jed Redwine and for his help with fieldwork and dissection. Many thanks to Emily Warschefsky for helpful discussions and lab assistance. Thanks to all of the friends and staff at Fairchild Tropical Botanic Garden, Montgomery Botanical Center, and the Center for Tropical Plant Conservation for support during my graduate studies. Specifically, a special thanks to Devon Powell for all her plant expertise, field assistance and patience in assisting me with any and all questions. 
To the amazing women who set me on this graduate path: Paula Rechner and Judy Dietert. Thank you for showing me that joyful, successful, powerful women with families do exist. You motivated me to pursue my dreams through your love, support, example and many care packages.

I want to also give gratitude to my friends and family both near and far for providing their support and encouragement. I owe the world to my superwoman Mom; thank you for always reminding me to never settle, take charge and to continue learning. To my minis, Lex and Sloane for motivating me to always be better than I am presently and to remain focused because our time is so precious. Lastly, to my husband Tim for endlessly giving his time, expertise, deliberate thinking and patience to any and all computer, statistical and morale issues. 


\begin{abstract}
OF THE THESIS
GENETIC STRUCTURE OF THE FLORIDA KEY TREE CACTUS, Pilosocereus robinii, USING RESTRICTION SITE ASSOCIATED DNA (RAD) MARKERS

by
\end{abstract}

Tonya Dee René Simons Fotinos

Florida International University, 2013

Miami, Florida

Professor Eric von Wettberg, Major Professor

Rare plant conservation efforts must utilize current genetic methods to ensure the evolutionary potential of populations is preserved. One such effort involves the Key Tree Cactus, Pilosocereus robinii, which is an endangered columnar cactus native to the Florida Keys. The populations have precipitously declined over the past decade because of habitat loss and increasing soil salinity from rising sea levels and storm surge. Nextgeneration DNA sequencing was used to assess the genetic structure of the cactus populations. Twenty individuals representative of both wild and extirpated cacti were chosen for Restriction Site Associated DNA (RAD) analysis. Samples processed using the HindIII and NotIII restriction enzymes produced 82,382,440 high quality reads used for genetic mapping, from which 5,265 Single Nucleotide Polymorphisms (SNPs) were discovered. The analysis revealed that the Keys' populations are closely related with little population differentiation. In addition, the populations display evidence of inbreeding and low genetic diversity. 


\section{TABLE OF CONTENTS}

CHAPTER

PAGE

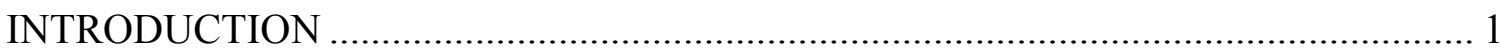

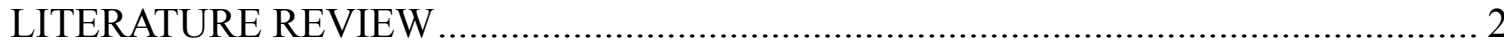

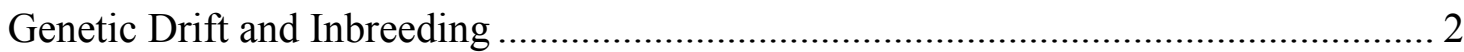

Effects on Genetic Diversity and Extinction ........................................................ 3

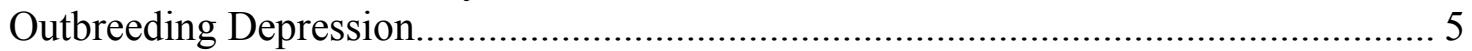

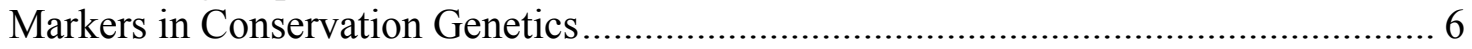

Study Species: Pilosocereus robinii................................................................... 7

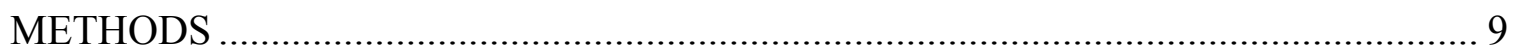

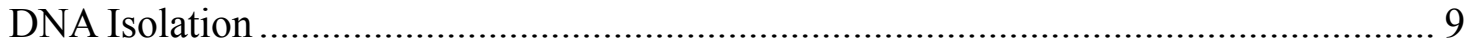

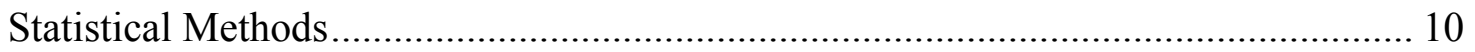

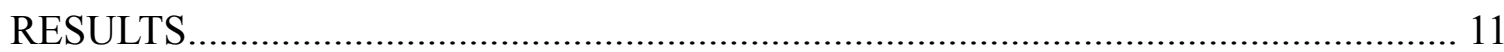

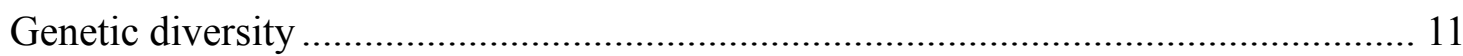

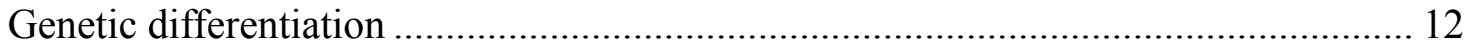

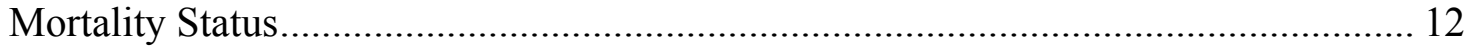

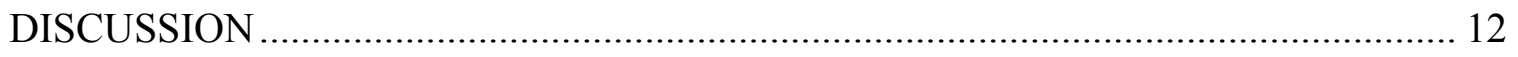

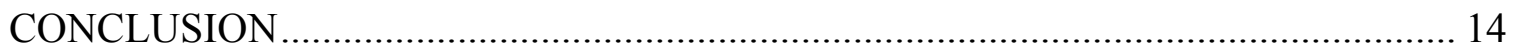

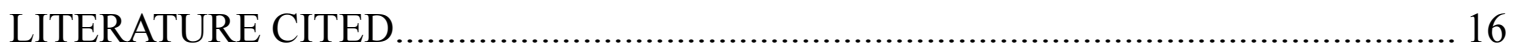

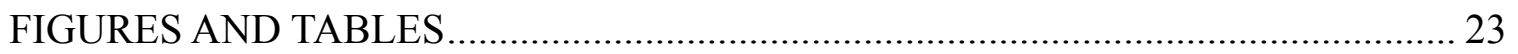




\section{LIST OF FIGURES AND TABLES}

Figure 1. Map of the populations of Pilosocereus robinii in the Florida Keys

Table 1. Sampling origin of individuals and mortality status

Table 2. Population genetic statisitcs 25

Table 3. Differentiation among populations based on pairwise $\mathrm{Phi}_{\mathrm{pt}}$ values

Figure 2. BIC graph from Discriminat Principal Compenents analysis showing $\mathrm{k}=2$

27

Figure 3. Plot of the principal coordinate analysis among populations

Figure 4. Plot of the principal coordinate analysis for mortality status 


\section{INTRODUCTION}

Biological systems around the globe are being plunged into crisis by the anthropogenic effects of landscape changes, habitat degradation and climate change (Barnosky et al. 2011; Lindenmayer \& Fischer 2006; Thomas et al. 2004; Tilman et al. 1994). Although there is a considerable threat across the globe, numerically the threat is highest in the biodiversity hotspots of the world. Of those hot spots, South Florida and the Caribbean are considered in the top five areas for conservation action because of the high level of endemism and threat (Myers et al. 2000). South Florida contains roughly 125 endemic species and is the northernmost limit of the distribution of many tropical species (Abrahamson 1984; Gann et al. 2002). Most of South Florida and the Caribbean are threatened by a sea level rise of $>1 \mathrm{~m}$ within the century (Maschinski et al. 2011).

As we enter into the sixth mass extinction in the fossil record, restoration of imperiled populations is a priority for mitigating this process (Barnosky et al. 2011). Repopulating previously occupied areas or supplementing a local population of existing individuals is a strategy that improves the odds that a population can recover from the fate of being the "living dead." To maximize the benefit of applying limited conservation funds, restoration projects must proceed with genetic information about the populations being augmented. Reintroduction efforts guided by genetic data have consistently had more successful outcomes (Falk et al. 1996; Godefroid et al. 2011; Maschinski \& Haskins 2012). More typically projects proceed with ecological information (Barrett \& Kohn 1991; Neale 2012) and some efforts have been successful (Menges 2008), but all could have benefited from genetic information. Undertaking conservation actions with genetic considerations will have a much higher chance of success and can bolster overall 
genetic diversity, thus improving a species' chance of persistence (Godefroid et al. 2011). Genetic factors affect population success at the same rate or faster than demographic or ecological factors (Frankham \& Ralls 1998; Saccheri et al. 1998) making their consideration just as vital as overall population numbers.

To inform restoration efforts effectively, genetic considerations must be incorporated. Plant populations with low numbers of individuals are affected by increased rates of genetic drift and inbreeding. Plants, by their sedentary nature, also have other genetic considerations such as outbreeding depression and clonality that require consideration in planning efforts. Supplementing a population with individuals can increase local genetic diversity and genetic information can drastically improve the odds of successful restoration of populations .

One such ongoing effort is the reintroduction of the United State federally endangered Key Tree cactus, Pilosocereus robinii, in South Florida. My project will contribute to the restoration of this species by examining the current genetic structure and diversity in the South Florida cactus populations utilizing a novel genetic analysis for an endangered species.

\section{LITERATURE REVIEW}

\section{Genetic Drift and Inbreeding}

Populations of small size are affected by an increase in two genetic processes, genetic drift and inbreeding. Genetic drift in a population is a change in allele frequency by random fluctuations caused by the sampling effect. In small populations, there are fewer copies of alleles than in larger populations and through the process of differential 
reproduction and sampling, the allele frequencies change faster because they are more driven by unpredictable fluctuations (Ellstrand \& Elam 1993).

Inbreeding is the mating of individuals that are genetically similar (Hedrick \& Kalinowski 2000). Selfing in plants, where an individual pollinates itself, is the most extreme form of inbreeding. Excessive inbreeding among individuals decreases the fitness of their offspring by expressing deleterious mutations in the homozygote form and by decreasing heterozygosity at loci that express overdominance (Charlesworth \& Willis 2009). Inbreeding is greater in small populations. Because there are fewer mating opportunities than in larger populations, individuals inevitably mate more with those closely related to themselves.

\section{Effects on Genetic Diversity and Extinction}

Genetic drift and inbreeding affect the fitness of populations by lowering overall genetic diversity. Effectively large population sizes must be maintained to minimize the effects of genetic drift and maintain the rarest of alleles (Lynch \& Lande 1998).

Conservation biology has often utilized genetics to help ensure the continued persistence of at-risk species and mitigate the effects of small population size. The main focus of conservation genetic studies has been to understand the current and historical genetic diversity of imperiled species in order to remove them from the extinction vortex that is often the fate of collapsing populations. The vortex is characterized by decreased genetic diversity, which decreases fitness, evolutionary potential, and reproductive potential; all of which reinforce each other (Frankham et al. 2002).

The key element needed to incorporate genetic analysis into conservation of rare and endangered species is to understand the current genetic structure of the populations, 
not merely to increase or stabilize population numbers. Well done genetic analysis should provide meaningful information so that management decisions can be executed to maintain the populations' ability to evolve rather than simply provide a defined number of individuals or geographic population size (Vogler \& Desalle 1994). To be able to preserve the evolutionary potential of a species, it is critical to understand the current level and distribution of genetic variation since this is the foundation of adaptation (Hamrick et al. 1991). The loss of genetic diversity has been correlated with decreased time to extinction and is therefore directly related to a species persistence (Frankham 2005; Frankham \& Ralls 1998; Gilpin \& Soulé 1986). The greater the genetic diversity of a population, the greater the probability of persistence (Frankham 2005; Lande \& Barrowclough 1987).

There is a relationship between the inbreeding coefficient and fitness indicators since inbreeding itself declines the fitness of populations. The relationship between fitness and inbreeding was demonstrated in Drospholia (Frankham 1995b; Miller \& Hedrick 2001) and also confirmed for terrestrial plants (Ouborg \& Vantreuren 1994). However, not all instances of heightened inbreeding actually lead to lower fitness in the population. Inbreeding in populations that are isolated, such as island populations or selfpollinating individuals, can result in the purging of deleterious mutations as they are expressed and selected against. Thus, the population rids itself of harmful alleles yet will display a high amount of inbreeding (Crnokrak \& Barrett 2002; Ellstrand \& Elam 1993). However, not every inbred population will undergo a purging effect because this process is stochastic and not deterministic (Miller \& Hedrick 2001). 
Inbreeding depression is affected by other factors in addition to population size, such as life history traits and environmental conditions, further complicating our ability to predict the genetic outcome of inbreeding depression and low population size. Plant species with a history of bottlenecks, colonization events, and lack of pollinators should show more self fertilization rates and display less inbreeding (Lande \& Schemske 1985). Furthermore, inbreeding depression is influenced by environmental conditions with populations under stress displaying more inbreeding (Armbruster \& Reed 2005). It has been difficult for conservation genetics to define and measure inbreeding depression appropriately, particularly in the case of plants where self-pollination occurs (Ellstrand \& Elam 1993; Frankham \& Ralls 1998). Inbreeding depression, taken as an estimate of the genetic variation or heterozygosity, nevertheless remains a central concern in small populations because it is negatively correlated with time to extinction (Ellstrand \& Elam 1993; Frankham \& Ralls 1998) and the magnitude of the effect of inbreeding is related to population size (Angeloni et al. 2011).

\section{Outbreeding Depression}

When crossbreeding occurs between locally adapted populations, the reduction in fitness of their progeny is referred to as outbreeding depression (Frankham et al. 2011). Unlike the heterosis of most outcrosses, the subsequent generations of individuals are maladapted to local conditions (McKay et al. 2005). Mating outside the local population can disrupt co-adapted gene complexes and have unpredicatable effects on epistatis (McKay et al. 2005). When local populations become genetically distinct based on adaptation to microsite conditions rather than genetic drift, reintroductions from genetically dissimilar individuals can dampen the local effect and reduce the overall 
fitness of the population (Hufford \& Mazer 2003). Plants are particularly prone to this effect because of their sedentary and often perennial lifestyle (Frankham 1995a; Hufford \& Mazer 2003). Understanding and identifying the genetic distinctiveness based on local adaptation of subpopulations is critical to restoration efforts so that outbreeding depression does not occur.

\section{Markers in Conservation Genetics}

Genetic diversity is a measure used to quantify the health of species of conservation concern. To examine genetic diversity, gene expression or the basis of heredity, markers must be chosen as proxies for the entire genome of the individuals. Ideally, the marker system chosen would be highly informative with little labor investment and would directly relate to the underlying adaptive genetic diversity in order to be effective. In the past thirty years, several markers have been utilized for study such as microsatellites, amplified fragment length polymorphisms (AFLPs), and alloyzymes (Avise 1994). Although useful, these markers are plagued by several shortcomings, particularly, lengthy development time for primers, variable reproducibility in different labs, and failure to cross amplify in related species or taxonomic groups (Seeb et al. 2011). Because of the laborious nature of discovery involved in these marker systems, the return on investment is usually 20 or less codominant markers for any particular organism. Also, many unknowingly utilize areas in the genome that are effectively neutral in terms of evolution and have limited application to interpret future adaptive potential.

However, the advent of next generation sequencing is making high throughput sequencing readily available for non-model organisms (Mardis 2008; Thomson et al. 
2010). Single nucleotide polymorphisms (SNPs) that are generated via next generation technologies have less genotyping error and increased statistical power (Allendorf et al. 2010; Hohenlohe et al. 2011). Restriction site associated DNA (RAD) is one such technique that can create hundreds to thousands of markers without the development of a primer system thus relieving the necessity for a lengthy discovery time for non-model organisms which could prove to be a very powerful tool for conservation (Davey \& Blaxter 2010; Rowe et al. 2011). This new technique has the ability to resolve fine scale patterns of variation allowing for resolution of past genetic flow or introgression (Hohenlohe et al. 2013). The statistical power of next generation sequencing and RAD methods can be directly applied to the conservation field for parameters that have been difficult to estimate such, as inbreeding coefficients and kinship. These methods have the potential to offer new insight into genetic questions that previous marker sets have been unable to address.

\section{Study Species: Pilosocereus robinii}

The focal species of this study is the Key Tree Cactus, Pilosocereus robinii, which is a federally endangered columnar cactus native to the tropical hardwood hammocks in the Florida Keys (Figure 1). As early as 1917, botanist John Small noted in his description that the cactus was rare in the Keys and in danger of extirpation as a consequence of colonization in the area (Small 1917). An extensive survey done in 1984 also noted declines in previously occupied areas (Adams \& Lima 1994). Although historically low, the number of remaining individuals has declined by more than $80 \%$ in the past decade because of continued habitat loss and environmental change (Goodman et al. 2012; USFWS 2010). The tropical hardwood hammocks of the Florida Keys are 
found on limestone outcroppings that represent the areas of highest elevation on the islands. These forests harbor a large number of endemic populations from the Caribbean region. These populations represent the northernmost distribution of most of these plant species, all of which are threatened by environmental change (Maschinski et al. 2011; Ross et al. 2009; USFWS 1999). Tropical hardwood hammocks are threatened currently and historically by urbanization, anthropogenically- induced change in fire frequency, conversion to agriculture, and climate change (Harveson et al. 2007; Ross et al. 2001; Ross et al. 2009; USFWS 1999). Rising sea level is of particular concern and, coupled with a recent increase in storm frequency and intensity, is predicted to have a potentially devastating impact on the small remaining populations in the Florida Keys (Maschinski \& Haskins 2012; Maschinski et al. 2011). Recent habitat surveys and experiments conducted by Fairchild Tropical Botanic Garden have suggested that increasing soil salinity has contributed to the Key Tree cactus' decline and that rapid climate change is the major driving cause (Goodman et al. 2012; Maschinski et al. 2011).

Pilosocereus robinii is part of a larger Pilosocereus complex of species found in the Caribbean but is the only representative of the genus that occurs in North America. The phylogenetic relationships of the various Pilosocereus populations in the Keys have been disputed since their discovery in 1838. Botanists John Torrey and Asa Gray first officially documented the cactus in 1838 as Cereus peruvianus (Torrey \& Gray 1838). The cactus was renamed six more times including genus and species names (see full history USFWS 1999). The Key Largo population has historically been treated as $P$. bahamensis (Britton) Byles \& G.D.Rowley (USFWS 2010). Despite this classification, both $P$. robinii and P. bahamensis have at times been grouped into the more widespread 
Caribbean-based species Pilosocereus polygonus (Lem.) Byles \& G.D.Rowley (Anderson 2001; Zappi 1994), but inclusion into P. polygonus has not been upheld elsewhere (ITIS 2013). Therefore, the relationship between the Key Largo population and the rest of the Keys population has to be resolved for appropriate management and reintroduction action for this species. The conservation effort for P. robinii would also benefit from clarification of the taxonomic relationships within the Pilososcereus genus across the entire Caribbean complex.

\section{METHODS}

\section{$\underline{\text { DNA Isolation }}$}

Root material was collected from twenty individuals from the Fairchild Tropical Botanic Garden ex situ collection which included 11 individuals that were alive in the wild and 9 individuals that were extirpated from the wild (Table 1). Root samples were collected by unearthing individually potted Pilosocereus stems from the Fairchild Tropical Botanic Garden holdings. The collection of stems from specific populations were taken as a proxy for field collection. Care was applied to ensure that root collections were connected to the main cactus stem and not adventitious sprouts. Root samples were then dried on Drierite $($ indicator 10-20 mesh desiccant (W.A. Hammond Drierite, Xenia, $\mathrm{OH}$ ) for a minimum of 24 hours and then DNA was extracted using a DNeasy® Plant Mini kit (Qiagen, Valencia, CA).

Restriction site associated DNA mapping (RAD) was used to identify SNPs in the twenty samples. Samples were processed at the Genome Center at the University of California at Davis. The DNA from P. robinii was digested using two restriction enzymes, Hind $I I I$ and Not $I I I$, and an adapter was ligated to the fragment overhanging 
ends that contained an identifier allowing the samples to be pooled. The product was sheared randomly then a second adapter was ligated to the ends. PCR was used to amplify the fragments and were then sequenced on an Illumnina sequencing platform. The cactus sample from Key Largo was used as a reference genome for mapping the other samples. A total of $151,829,113$ reads using the Illumina Hi-Seq next generation DNA sequencer were recovered. After quality filtering, 82,382,440 high quality (HQ) reads were used for mapping. The high quality reads were used as a reference to recover 5,265 single nucleotide polymorphisms (SNPs) for analysis. Additionally, 2,215 microsatellite loci were identified from the reference genome, which could be used for future genetic studies.

\section{$\underline{\text { Statistical Methods }}$}

Genetic diversity among the populations was assessed using the program GenAlEx 6.5b3, which determined the percentage of polymorphic loci (p), the observed heterozygosity $\left(\mathrm{H}_{\mathrm{O}}\right)$, and expected heterozygosity $\left(\mathrm{H}_{\mathrm{E}}\right)$ across the population samples (Peakall \& Smouse 2012). Global estimates of the inbreeding coefficient ( $\left.\mathrm{F}_{\mathrm{IS}}\right)$ for each population were calculated using Genepop in the method of Weir and Cockerham (1984). Global deviations from Hardy-Weinberg equilibrium for each population were also calculated using Genepop 4.2 with 10,000 dememorization steps, 20 batches with 5,000 iterations per batch (Raymond \& Rousset 1995; Rousset 2008).

The program GenAlEx was used to test for genetic differentiation within and among stands of cacti using an analysis of molecular variance (AMOVA) (Excoffier et al. 1992) among populations (with $p$-values obtained after 9999 permutations) and $\mathrm{Phi}_{\mathrm{pt}}$ pairwise comparisons between populations. 
There are several statistical approaches for clustering genetic data to find areas of diversity among populations. Discriminant analysis of principal components (DAPC) was chosen because the method has few assumptions and an ability to refine the differentiation between populations to minimize the within population differences, thus yielding reliable population information (Jombart et al. 2010). This analysis was conducted using the R statistical environment with the package adegenet (Jombart \& Ahmed 2011). Principal Coordinate Analyses (PCO) among all the individuals included in our study was computed with GenAlEx based on the algorithm developed by Orloci (1978). Prior to this analysis, these data were converted to pairwise individual genetic distances (Smouse \& Peakall 1999), standardized, and formatted as a covariance matrix. Lastly, to examine whether the mortality status of each individual has a genetic component, an AMOVA and PCO were performed in GenAlEx.

\section{RESULTS}

\section{Genetic diversity}

Genetic diversity was relatively low across the populations sampled. The percent of polymorphic loci across the populations ranged from $6.27 \%$ to $64.16 \%$ (Table 2 ). Although relatively low, the observed heterozygosity estimates were generally higher than what was expected across the populations. Inbreeding coefficients were all positive, indicating a deficit of heterozygotes, consistent with inbred populations. The Lower Matecumbe Key population displayed less inbreeding than the other populations with a value closer to zero. All populations significantly deviated from Hardy-Weinberg equilibrium (Table 2). 


\section{$\underline{\text { Genetic differentiation }}$}

We found a small amount of subdivision in populations with pairwise $\mathrm{Phi}_{\mathrm{PT}}$ values of 0.436 and 0.395 (Table 3). Only four pairwise comparisons were significant at $\mathrm{P}<0.05$ with Big Pine having the most numerous pairwise differences from the rest of the samples. Key Largo had the least amount of variation, displaying zero difference between every population except Lower Matecumbe. Additionally, AMOVA indicated that $86 \%$ of the genetic variation was shared across the group and only $14 \%$ of the overall variation was restricted to a particular population $(\mathrm{F}=0.139, \mathrm{p}=0.020)$.

The principal coordinate analysis showed that $39.69 \%$ and $16.62 \%$ of the genetic variation was explained on the first two axes, respectively. The Lower Matecumbe population grouped together in the lower half (Figure 1). The two Key Largo samples did not cluster in the same quadrant suggesting this clump of stems is not clonal. The subdivision of the two populations is further supported by the DAPC cluster analysis which revealed the true number of populations as two $[\mathrm{k}=2]$ (Figure 3).

\section{$\underline{\text { Assessing Genetic differences between Living and Dead Cacti }}$}

The examination of a genetic component between living and extirpated cacti showed that only $1 \%$ of the variation were specific to the plant status in the wild and was not significant $(\mathrm{F}=0.010, \mathrm{p}=0.340)$. The $\mathrm{PCO}$ analysis did not reveal a relationship between mortality status and genetic relatedness (Figure 5).

\section{DISCUSSION}

The populations of Pilosocereus robinii in the Florida Keys display considerable amounts of inbreeding and low levels of genetic diversity. The results are consistent with 
the species' having a history of bottlenecks and colonization. Global inbreeding coefficients for $P$. robinii were all high which indicates populations that are characterized by inbreeding. There was very little genetic difference between the stands of cacti in the Florida Keys, with pairwise $\mathrm{Phi}_{\mathrm{pt}}$ values were relatively low. The AMOVA and pairwise comparisons indicated that most of the genetic variation is shared among the group as a whole rather than between individual populations. Although some values of $\mathrm{Phi}_{\mathrm{pt}}$ indicate low levels of population differentiation, others are relatively high particularly those between Big Pine and Lower Matecumbe. Big Pine Key had the most significant deviations in the pairwise comparison and according to the PCO diagram had the greatest breadth of genetic differentiation. Although Lower Matecumbe grouped out in the PCO diagram in a separate quadrant suggesting some unique variation, only one pairwise comparison was significant.

The Key Largo cactus has been thought to perhaps be a large clonal stand but the PCO diagram and the sequence data do not support this. They demonstrate that the putative clonal stand on Key Largo is in fact made up of separate individuals since truly clonal individuals would be represented by points that fall very near one another or right on top of one another. This cacti stand is known to be a prolific reproducer in the wild and one of the few individuals that does so. The low amount of differentiation between Key Largo and the other populations suggests that the Key Largo population is closely related to the settlement of Pilosocereus in the lower Keys. On the basis of the PCO and raw sequences, the individuals sampled are not completely clonal and reproduction has taken place in the wild at some point in the past. Currently, the Key Largo plant is the only cactus to set fruit successfully in the wild. 
Additionally, the DAPC results confirm a true number of populations as $\mathrm{k}=2$, which is supported by the PCO diagram showing Lower Matecumbe distinct from the result of the cacti. The lack of significant pairwise $\mathrm{Phi}_{\mathrm{pt}}$ values could be based on the low sample size.

The comparisons of living versus extirpated cacti indicate that there is not a genetic basis for morality or survival that is detectable in this study. The Key Tree Cactus is known to be adversely affected by salinity levels and mortality has been demonstrated to be directly related to the surrounding levels of salinity in the soil (Goodman et al. 2012). However, the genetic basis of salinity tolerance in plants has proved challenging to unravel, so whether extirpation has a detectable genetic relation to soil salinity cannot currently be determined from this data.

Recent studies investigating the genetic diversity and clonality of Pilosocereus species in South America have revealed a high amount of genetic diversity with expected heterozygosity estimates of 0.3 (Figueredo et al. 2010; Moraes et al. 2005). An adequate indicator of differentiation is typically an $\mathrm{F}_{\mathrm{ST}}$ value above 0.30 and all pairwise comparisons for the Key Tree Cactus populations were below this threshold. Many rare species, however, when compared to their more widespread relatives appear deficient in genetic diversity (Hamrick \& Godt 1996).

\section{CONCLUSION}

The lack of differentiation from the stand of cacti on Key Largo compared to the rest of the populations could indicate that the Key Largo population was established by an initial colonizing event and could be the mother plant to the rest of the $P$. robinii in the 
Florida Keys. Further testing and comparisons between the Pilosocereus genus in the Caribbean can elucidate this issue. The Key Largo stand of cacti appears more similar to all of the rest of the populations than they do to each other. The lack of significant deviations from Key Largo to the rest of the populations lends credibility to the argument than $P$. bahamensis is in fact $P$. robinii since this particular cactus is more similar to the rest of the cacti in the Keys.

Given the limited knowledgebase concerning the taxonomic relationship of this genus in the Caribbean, further genetic work must be completed to reveal the relationship of this North American-based species to the rest of Pilosocereus. An inclusion of Bahamian and Dominican Republic samples of P. polygonus is currently being planned for analysis in the dataset to answer these remaining questions.

The reintroduction of Pilosocereus robinii into the Florida Keys is ongoing. The first transplant population was planted August 2012. Most of the transplants are thriving, although some mortality has occurred. My genetic analysis suggests that the plantings have not interfered with population structure across the Keys, and that lower Keys material can be safely transplanted to higher ground in the upper Keys. There is little genetic evidence to suggest that plantings need to remain within the population of origin. Lower Matecumbe and Long Key are priorities for collection since they contain distinct variation and Big Pine Key for its greater amount of genetic diversity. 


\section{LITERATURE CITED}

Abrahamson, W. G. 1984. Species responses to fire on the Florida Lake Wales Ridge. American Journal of Botany 71:35-43.

Adams, R. M., and A. N. Lima. 1994. The natural history of the Florida keys tree cactus,Pilosocereus robinii in U.S.F.W. Service, editor, Jacksonville, Florida.

Allendorf, F. W., P. A. Hohenlohe, and G. Luikart. 2010. Genomics and the future of conservation genetics. Nature Reviews Genetics 11:697-709.

Anderson, E. F. 2001. The Cactus Family. Timber Press, Portland, Oregon.

Angeloni, F., N. J. Ouborg, and R. Leimu. 2011. Meta-analysis on the association of population size and life history with inbreeding depression in plants. Biological Conservation 144:35-43.

Armbruster, P., and D. H. Reed. 2005. Inbreeding depression in benign and stressful environments. Heredity 95:235-242.

Avise, J. C. 1994. Molecular Markers, Natural History, and Evolution. Chapman and Hall, New York.

Barnosky, A. D., N. Matzke, S. Tomiya, G. O. U. Wogan, B. Swartz, T. B. Quental, C. Marshall, J. L. McGuire, E. L. Lindsey, K. C. Maguire, B. Mersey, and E. A. Ferrer. 2011. Has the Earth's sixth mass extinction already arrived? Nature 471:51-57.

Barrett, S. H., and J. R. Kohn. 1991. Genetic and Evolutionary Consequences of Small Population Size in Plants: Implications for Conservation. Pages 3-30 in D. A. Falk, and K. E. Holsinger, editors. Genetics and Conservation of Rare Plants. Oxford University Press, New York.

Charlesworth, D., and J. H. Willis. 2009. Fundamental concepts in genetics: The genetics of inbreeding depression. Nature Reviews Genetics 10:783-796.

Crnokrak, P., and S. C. H. Barrett. 2002. Purging the genetic load: A review of the experimental evidence. Evolution 56:2347-2358. 
Davey, J. L., and M. W. Blaxter. 2010. RADSeq: next-generation population genetics. Briefings in Functional Genomics 9:416-423.

Ellstrand, N. C., and D. R. Elam. 1993. Population genetic consequences of small population size - implications for plant conservation. Annual Review of Ecology and Systematics 24:217-242.

Excoffier, L., P. E. Smouse, and J. M. Quattro. 1992. Analysis of molecular variance inferred from metric distances among DNA haplotypes - application to human mitrochondrial-DNA restriction data. Genetics 131:479-491.

Falk, D. A., C. I. Millar, M. Olwell, and (Eds.) 1996. Restoring Diversity: strategies for reintroduction of endangered plants. Island Press, Washington, D.C.

Figueredo, C. J., J. M. Nassar, A. E. Garcia-Rivas, and J. A. Gonzalez-Carcacia. 2010. Population genetic diversity and structure of Pilosocereus tillianus (Cactaceae, Cereeae), a columnar cactus endemic to the Venezuelan Andes. Journal of Arid Environments 74:1392-1398.

Frankham, R. 1995a. Conservation genetics. Annual Review of Genetics 29:305-327.

Frankham, R. 1995b. Inbreeding and extinction - a threshold effect. Conservation Biology 9:792-799.

Frankham, R. 2005. Genetics and extinction. Biological Conservation 126:131-140.

Frankham, R., J. D. Ballou, M. D. B. Eldridge, R. C. Lacy, K. Ralls, M. R. Dudash, and C. B. Fenster. 2011. Predicting the Probability of Outbreeding Depression. Conservation Biology 25:465-475.

Frankham, R., Ballou, J. D., \& Briscoe, D. A. 2002. Introduction to conservation genetics. Cambridge University Press, Cambridge, UK.

Frankham, R., and K. Ralls. 1998. Conservation biology - Inbreeding leads to extinction. Nature 392:441-442.

Gann, G. D., K. A. Bradley, and S. W. Woodmansee. 2002. Rare Plants of South Florida: Their history, conservation, and restoration, The Institute of Regional Conservation. Retrieved from: http://regionalconservation.org/ircs/RSFNPH/RSFNPHdefault.asp. 
Gilpin, M. E., and M. E. Soulé. 1986. Minimum Viable Populations and Processes of Species Extinctions in M. E. Soule, editor. Conservation Biology: The Science of Scarcity and Diversity. Sinauer Associates, Massachusetts.

Godefroid, S., C. Piazza, G. Rossi, S. Buord, A. D. Stevens, R. Aguraiuja, C. Cowell, C. W. Weekley, G. Vogg, J. M. Iriondo, I. Johnson, B. Dixon, D. Gordon, S. Magnanon, B. Valentin, K. Bjureke, R. Koopman, M. Vicens, M. Virevaire, and T. Vanderborght. 2011. How successful are plant species reintroductions? Biological Conservation 144:672-682.

Goodman, J., J. Maschinski, P. Hughes, J. McAuliffe, J. Roncal, D. Powell, and L. O. Sternberg. 2012. Differential Response to Soil Salinity in Endangered Key Tree Cactus: Implications for Survival in a Changing Climate. Plos One 7.

Hamrick, J., M. Godt, D. Murawski, and M. Lovelass. 1991. Correlations between species traits and allozyme diversity: implications for conservation biology. Pages 75-86. In: Falk DA, editors, editor. Genetics and conservation of rare plants. Oxford University Press, New York.

Harveson, P. M., R. R. Lopez, B. A. Collier, and N. J. Silvy. 2007. Impacts of urbanization on Florida Key deer behavior and population dynamics. Biological Conservation 134:321-331.

Hedrick, P. W., and S. T. Kalinowski. 2000. Inbreeding depression in conservation biology. Annual Review of Ecology and Systematics 31:139-162.

Hohenlohe, P. A., S. J. Amish, J. M. Catchen, F. W. Allendorf, and G. Luikart. 2011. Next-generation RAD sequencing identifies thousands of SNPs for assessing hybridization between rainbow and westslope cutthroat trout. Molecular Ecology Resources 11:117-122.

Hohenlohe, P. A., M. D. Day, S. J. Amish, M. R. Miller, N. Kamps-Hughes, M. C. Boyer, C. C. Muhlfeld, F. W. Allendorf, E. A. Johnson, and G. Luikart. 2013. Genomic patterns of introgression in rainbow and westslope cutthroat trout illuminated by overlapping paired-end RAD sequencing. Molecular Ecology. doi: $10.1111 / \mathrm{mec} .12239$.

Hufford, K. M., and S. J. Mazer. 2003. Plant ecotypes: genetic differentiation in the age of ecological restoration. Trends in Ecology \& Evolution 18:147-155. 
ITIS. 2013. Integrated Taxonomic Information System. Retrived from: http://www.itis.gov/servlet/SingleRpt/SingleRpt?search_topic=TSN\&search_valu $\mathrm{e}=19855$.

Jombart, T., and I. Ahmed. 2011. adegenet 1.3-1: new tools for the analysis of genomewide SNP data. Bioinformatics 27:3070-3071.

Jombart, T., S. Devillard, and F. Balloux. 2010. Discriminant analysis of principal components: a new method for the analysis of genetically structured populations. Bmc Genetics 11.

Lande, R., and G. F. Barrowclough. 1987. Effective population size, genetic variation and their use in population management. Pages 87-123 in M. E. Soule, editor. Viable populations for conservation. Cambridge University Press, Cambridge, England.

Lande, R., and D. W. Schemske. 1985. The evolution of self-fertilization and inbreeding depression in plants I. Genetic Models. Evolution 39:24-40.

Lindenmayer, D., and J. Fischer 2006. Habitat Fragmentation And Landscape Change: An Ecological And Conservation Synthesis. Island Press, Washington, D.C.

Lynch, M., and R. Lande. 1998. The critical effective size for a genetically secure population. Animal Conservation 1:70-72.

Mardis, E. R. 2008. The impact of next-generation sequencing technology on genetics. Trends in Genetics 24:133-141.

Maschinski, J., and K. E. Haskins 2012. Plant Reintroduction in a Changing Climate: Promises and Perils. Island Press.

Maschinski, J., M. Ross, H. Liu, J. O’Brien, E. von Wettberg, and K. Haskins. 2011. Sinking Ships: Conservation Alternatives for Endemic Taxa Threatened by Sea Level Rise. Climate Change available 107:147-167

McKay, J. K., C. E. Christian, S. Harrison, and K. J. Rice. 2005. "How local is local?" - A review of practical and conceptual issues in the genetics of restoration. Restoration Ecology 13:432-440.

Menges, E. S. 2008. Restoration demography and genetics of plants: when is a translocation successful? Australian Journal of Botany 56:187-196. 
Miller, P. S., and P. W. Hedrick. 2001. Purging of inbreeding depression and fitness decline in bottlenecked populations of Drosophila melanogaster. Journal of Evolutionary Biology 14:595-601.

Moraes, E. M., A. G. Abreu, S. C. S. Andrade, F. M. Sene, and V. N. Solferini. 2005. Population genetic structure of two columnar cacti with a patchy distribution in eastern Brazil. Genetica 125:311-323.

Myers, N., R.A. Mittermeier, C. G. Mittermeier, G.B. daFonseca, and J. Kent. 2000. Biodiversity hotspots for conservation priorities. Nature 403:853-858.

Neale, J. 2012. Genetic Considerations in Rare Plant Reintroduction: Practical Applications (or How Are We Doing?). Pages 71-88 in J. Maschinski, and K. E. Haskins, editors. Plant reintroduction in a changing climate: Promises and Perils. Island Press, Washington D.C.

Orloci, L. 1978. Multivariate analysis in vegetation research. Springer, New York.

Ouborg, N. J., and R. Vantreuren. 1994. The significance of genetic erosion in the process of extinction IV. Inbreeding load and heterosis in relation to population size in the mint Salvia pratensis. Evolution 48:996-1008.

Peakall, R., and P. E. Smouse. 2012. GenAlEx 6.5: genetic analysis in Excel. Population genetic software for teaching and research-an update. Bioinformatics 28:25372539.199

Raymond, M., and F. Rousset. 1995. GENEPOP (Version-1.2) - Population genetics software for exact tests and ecumenicism. Journal of Heredity 86:248-249.

Ross, M. S., M. Carrington, L. J. Flynn, and P. L. Ruiz. 2001. Forest succession in tropical hardwood hammocks of the Florida keys: Effects of direct mortality from Hurricane Andrew. Biotropica 33:23-33.

Ross, M. S., J. J. O'Brien, R. G. Ford, K. Q. Zhang, and A. Morkill. 2009. Disturbance and the rising tide: the challenge of biodiversity management on low-island ecosystems. Frontiers in Ecology and the Environment 7:471-478.

Rousset, F. 2008. GENEPOP ' 007: a complete re-implementation of the GENEPOP software for Windows and Linux. Molecular Ecology Resources 8:103-106. 
Rowe, H. C., S. Renaut, and A. Guggisberg. 2011. RAD in the realm of next-generation sequencing technologies. Molecular Ecology 20:3499-3502.

Saccheri, I., M. Kuussaari, M. Kankare, P. Vikman, W. Fortelius, and I. Hanski. 1998. Inbreeding and extinction in a butterfly metapopulation. Nature 392:491-494.

Seeb, J. E., G. Carvalho, L. Hauser, K. Naish, S. Roberts, and L. W. Seeb. 2011. Singlenucleotide polymorphism (SNP) discovery and applications of SNP genotyping in nonmodel organisms. Molecular Ecology Resources 11:1-8.

Small, J. K. 1917. The tree cacti of the Florida Keys. Journal of the New York Botanical Garden 18:199-203.

Smouse, P. E., and R. Peakall. 1999. Spatial autocorrelation analysis of individual multiallele and multilocus genetic structure. Heredity 82:561-573.

Thomas, C. D., A. Cameron, R. E. Green, M. Bakkenes, L. J. Beaumont, Y. C. Collingham, B. F. N. Erasmus, M. F. de Siqueira, A. Grainger, L. Hannah, L. Hughes, B. Huntley, A. S. van Jaarsveld, G. F. Midgley, L. Miles, M. A. OrtegaHuerta, A. T. Peterson, O. L. Phillips, and S. E. Williams. 2004. Extinction risk from climate change. Nature 427:145-148.

Thomson, R. C., I. J. Wang, and J. R. Johnson. 2010. Genome-enabled development of DNA markers for ecology, evolution and conservation. Molecular Ecology 19:2184-2195.

Tilman, D., R. M. May, C. L. Lehman, and M. A. Nowak. 1994. Habitat destruction and the extinction debt. Nature 371:65-66.

Torrey, J., and A. Gray. 1838. A Flora of North America. Reprinted (1968). Hafner Press, New York, New York.

USFWS. 1999. Multi-species Recovery Plan for South Florida. Accessed online at: ecos.fws.gov/docs/recovery_plans/1999/990518.pdf.

USFWS. 2010. Key tree-cactus (Pilosocereus robinii) 5-Year Review: Summary and Evaluation.

Vogler, A. P., and R. Desalle. 1994. Diagnosing units of conservation management. Conservation Biology 8:354-363. 
Weir, B. S., and C. C. Cockerham. 1984. Estimating F-statistics for the analysis of population structure. Evolution 38:1358-1370.

Zappi, D. 1994. Pilosocereus: The genus in Brazil, David Hunt, Dorset England. 
Figure 1. Map showing the populations of Pilosocereus robinii in Florida including the ex situ collection held at Fairchild Tropical Botanic Garden in Coral Gables, Florida

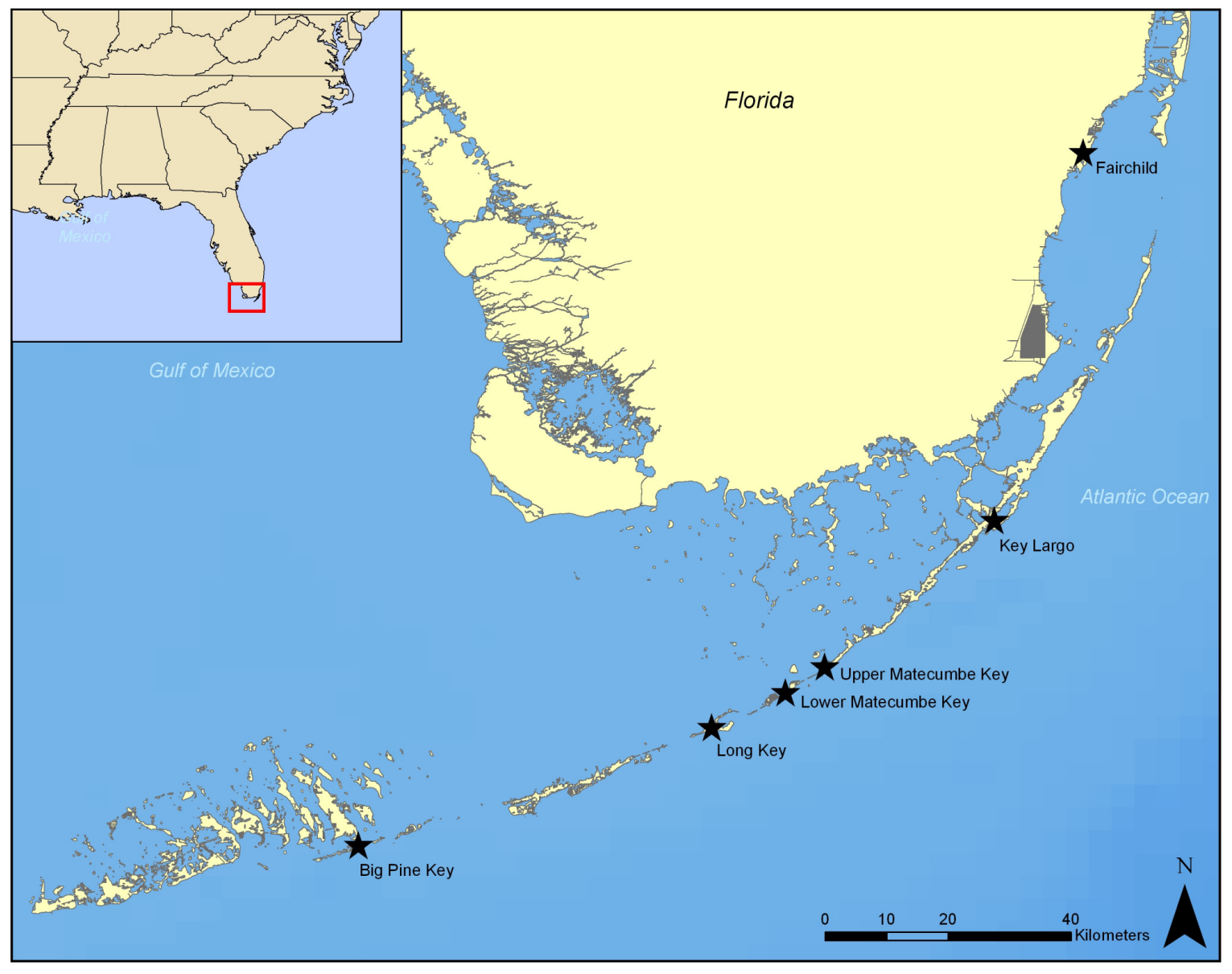


Table 1. Individuals from the Fairchild Tropical Botanic Garden ex situ collection of Pilosocereus robinii that were included in the genetic analysis and their population of origin.

\begin{tabular}{|r|c|c|}
\hline & Total & Dead in wild $^{1}$ \\
\hline Big Pine Key & 7 & 5 \\
\hline Long Key & 2 & 1 \\
\hline Upper Matecumbe Key - stand 1 & 4 & 3 \\
\hline Upper Matecumbe Key - stand 2 & 2 & 0 \\
\hline Lower Matecumbe Key & 3 & 0 \\
\hline Key Largo & 2 & 0 \\
\hline Total & 20 & 9 \\
\hline
\end{tabular}

${ }^{1}$ In situ plant subsequently extirpated after the vegetative ex situ collection was made beginning in 2007 


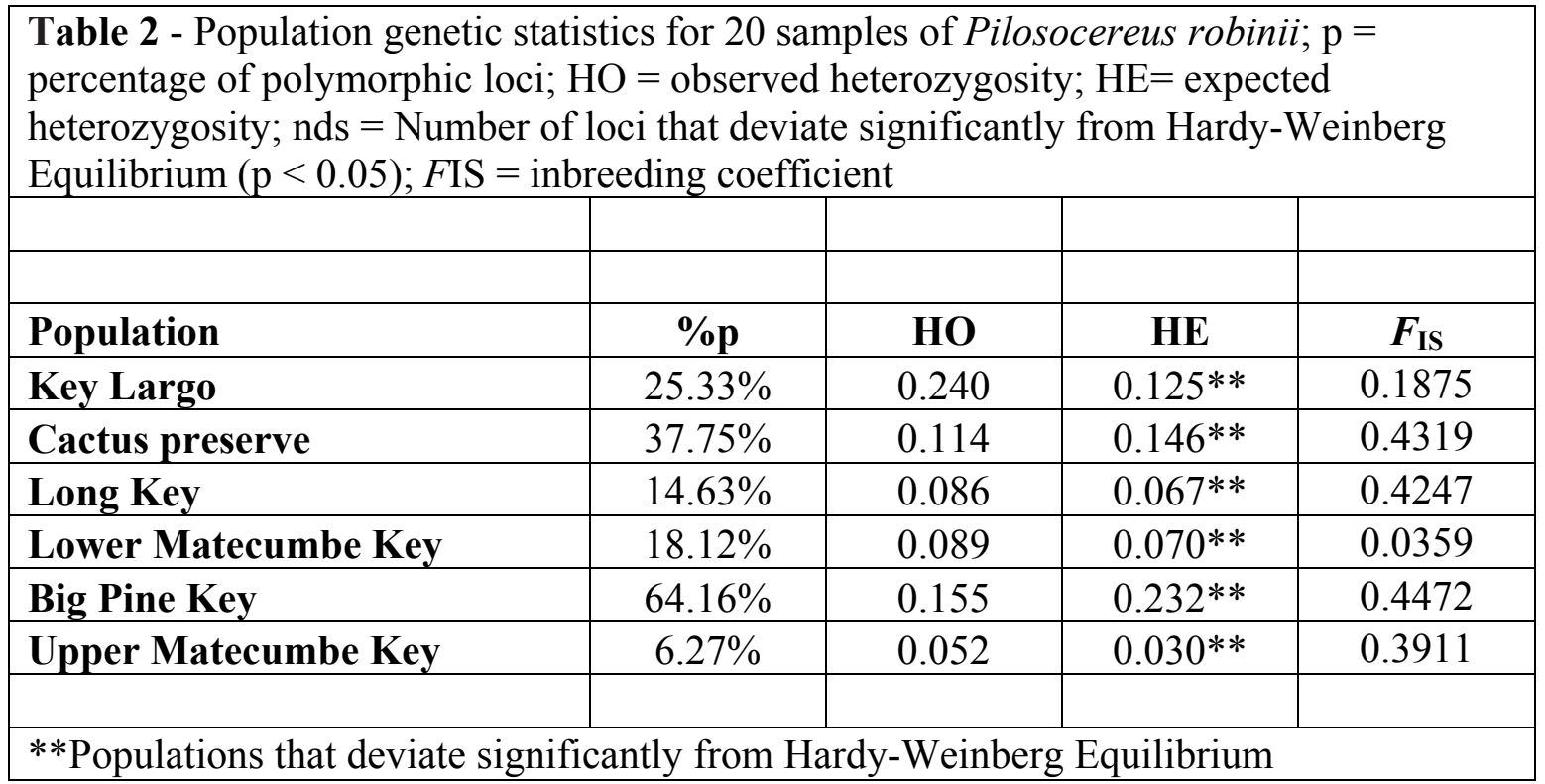




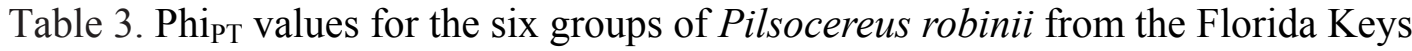
(** shows significance at 0.05 for pairwise Phipt values)

\begin{tabular}{|l|l|l|l|l|l|}
\hline & Key Largo & $\begin{array}{l}\text { Cactus } \\
\text { preserve }\end{array}$ & $\begin{array}{l}\text { Long } \\
\text { Key }\end{array}$ & $\begin{array}{l}\text { Lower } \\
\text { Matecumbe }\end{array}$ & Big Pine \\
\hline Cactus preserve & 0.000 & & & & \\
\hline Long Key & 0.000 & 0.233 & & & \\
\hline Lower Matecumbe & 0.095 & $0.292^{* *}$ & 0.395 & & \\
\hline Big Pine & 0.000 & $0.134^{* *}$ & $0.115^{* *}$ & $0.214^{* *}$ & \\
\hline Upper Matecumbe & 0.000 & 0.243 & 0.087 & 0.436 & 0.151 \\
\hline
\end{tabular}


Figure 3. This graph shows the output of the DAPC analysis. Bayesian information criterion (BIC) is provided for different numbers of clusters and the chosen number of clusters (2) is circled in red.

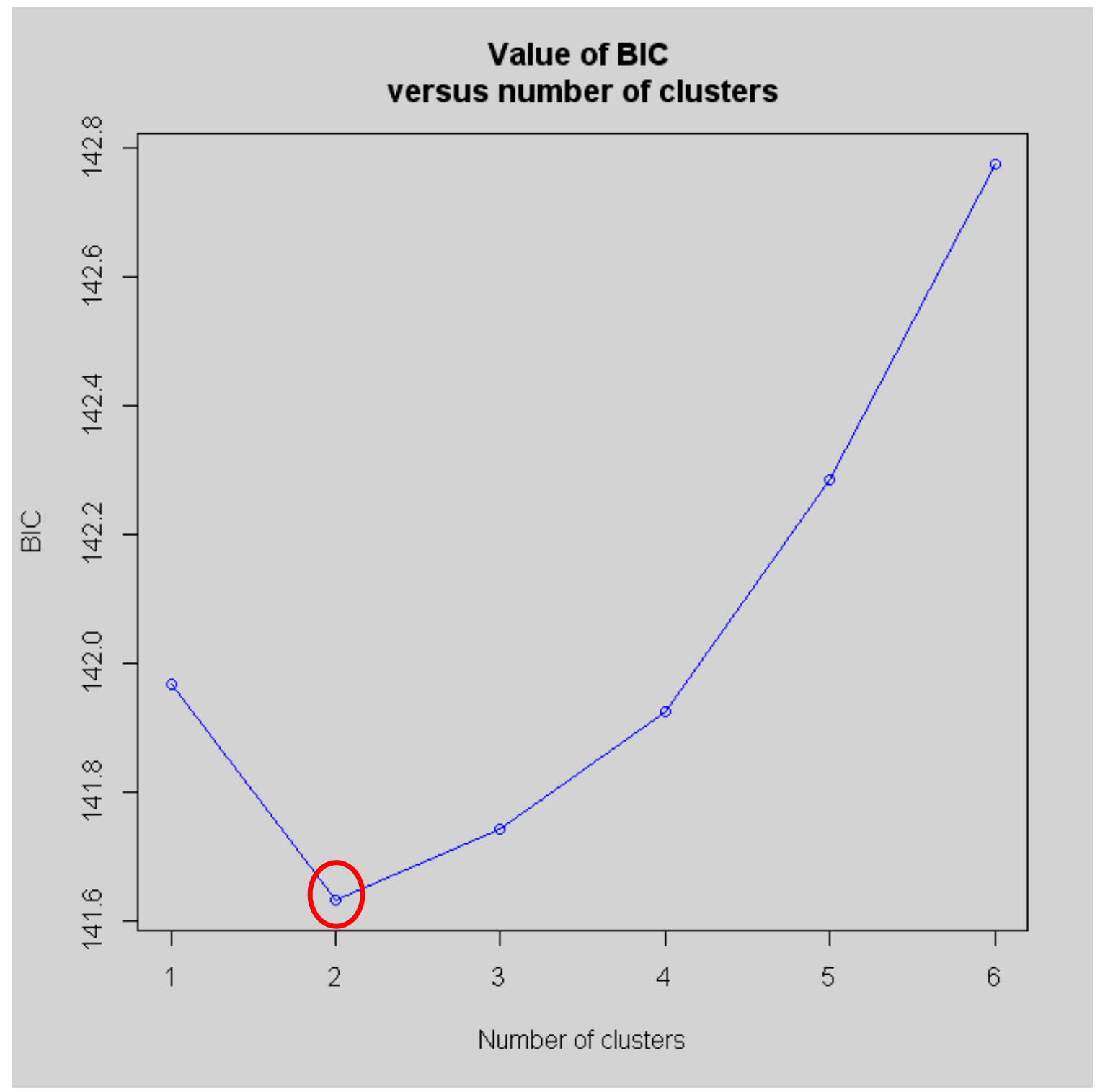


Figure 4. Two dimensional plot of the PCO for the six populations of Pilosocereus robinii in the Florida Keys. The first axis explained $37.69 \%$ and the second axis represents $16.63 \%$ of the total variation.

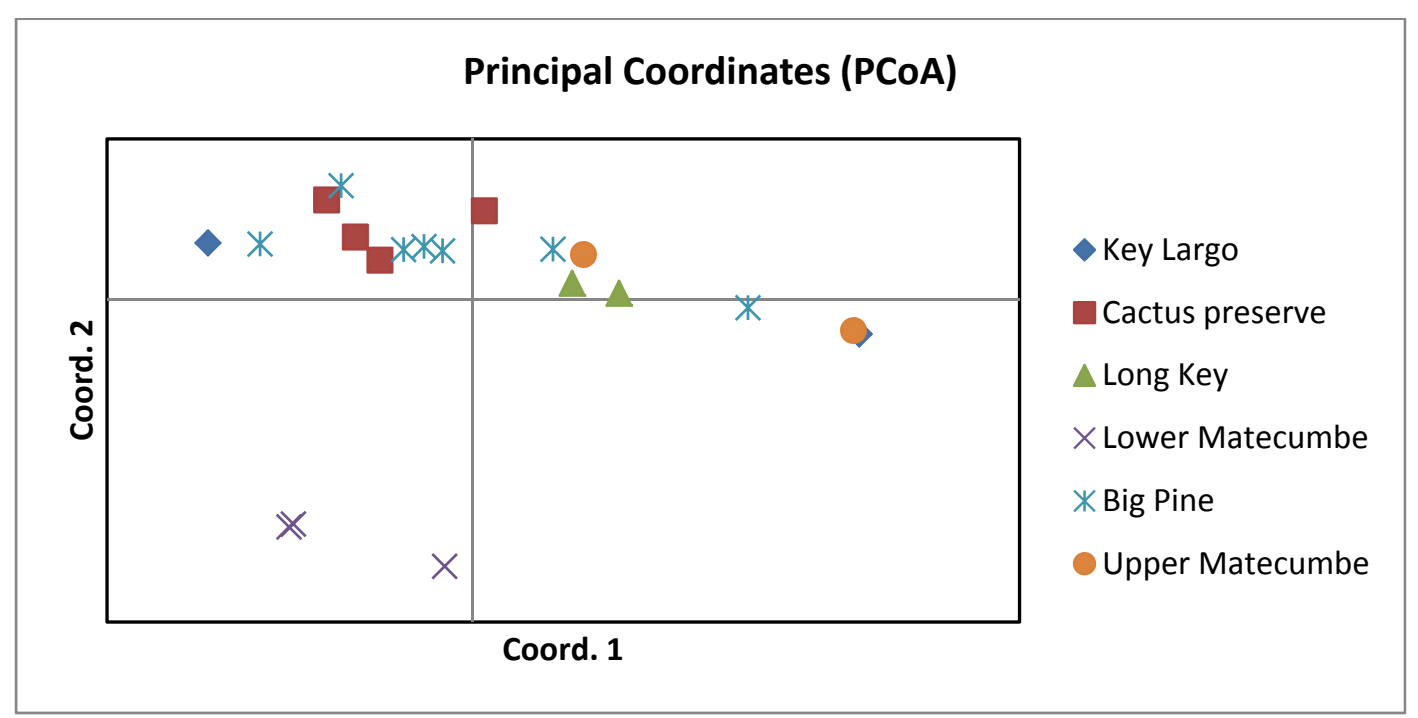


Figure 5. Two dimensional plot of the PCO for the mortality status of Pilosocereus robinii. The first axis explained $37.69 \%$ and the second axis represents $16.63 \%$ of the total variation.

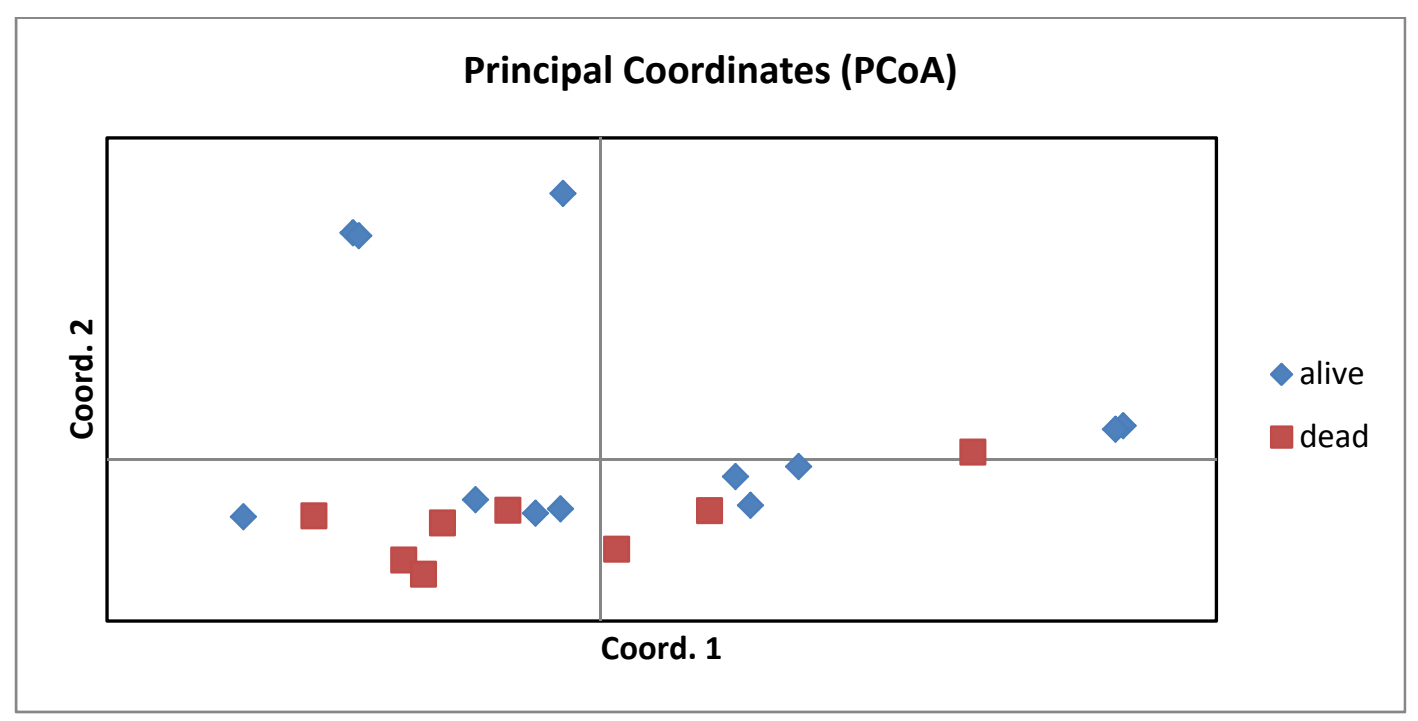

